\title{
Geochemical characteristics and environmental implications of the elements of Qingshan Group on the Zhougezhuang Section, Shandong Province, China
}

\footnotetext{
MANJIE Li ${ }^{1 *}$, YAOQI ZHOU ${ }^{1}$, TENGFEI ZHOU ${ }^{1}$

${ }^{1}$ China University of Petroleum, Qingdao, China.

(*correspondence: 2941949941@qq.com)

The Lower Cretaceous Qingshan Group on the Zhougezhuang Section, Jimo, Shandong Province is a newly discovered stratums located in the edge of the Jiaolai Basin. The paleoclimatic changes and REDOX conditions in this area are still unknown. The primary elements, trace elements and rare earth elements in the sedimentary rocks can preserve the original geochemical information well and they are sensitive to the changes of sedimentary water body, which reflects the paleosedimentary environment. 12 samples including 3 mudstone, 4 limestone and 5 at different stratums from Zhougezhuang Section are tested for major elements, trace elements and rare earth elements in the research. The paleosedimentary environment is analyzed quantitatively and semi-quantitatively by combining petrological and sedimentology characteristics. A series of geochemical characteristics such as the values of $\mathrm{SiO} 2 / \mathrm{Al} 2 \mathrm{O} 3, \mathrm{CaO} /(\mathrm{Fe}+\mathrm{CaO})$, $\mathrm{V} /(\mathrm{V}+\mathrm{Ni}), \mathrm{Th} / \mathrm{U}, \mathrm{Sr} / \mathrm{Ba}$ and $\mathrm{Sr} / \mathrm{Cu}$ are analyzed.Studies show that the geochemical characteristics of samples indicate the lacustrine sedimentary environment. The paleoenvironment and REDOX conditions of Qingshan Group is semi-saline water, oxidative, dry and hot climate environment. The geotectonic setting is probably continental island arc and active continental margin.Our research improves the study of the paleoenvironment and REDOX conditions of Zhougezhuang Section and provides the basis for further exploration of the organic matter enrichment mechanism and the evolution of source rocks.
} 